\title{
O DISPOSITIVO COLONIAL: ENTRE A ARQUEOGENEALOGIA DE MICHEL FOUCUALT E OS ESTUDOS DECOLONIAIS
}

\author{
Discourse, archeogenealogy and Colonial Dispositive in the convergence between \\ Foucault and Decolonial Studies
}

\author{
Flávia Marinho LISBÔA \\ Universidade Federal Rural da Amazônia (UFRA)
}

http://orcid.org/0000-0001-7262-7716

\begin{abstract}
RESUMO: Este artigo busca estabelecer relações teórico-conceituais entre o discurso, a arqueogenealogia foucaultiana e a colonialidade, evidenciando como os estudos discursivos assentados nas/pelas lutas sociais podem ser potencializados pela noção de "genealogia" como a insurgência dos saberes subalternos, compreensão primordial nas proposições de Foucault e dos estudos sobre a colonialidade. Neste ponto, defende-se a possibilidade de um entrelaçamento entre ambos, o que é pontuado por meio da divisão do trabalho em duas seções de discussão: a primeira trata das percepções de análise discursiva de Michel Foucault, diferenciando as propostas arqueológica, genealógica e arqueogenealógica; e a segunda dá continuidade às discussões genealógicas, convergindo para a ideia de Dispositivo Colonial como construto conceitual que também reforça a discussão sobre a aliança proposta.
\end{abstract}

PALAVRAS-CHAVE: Análise do Discurso. Foucault. Genealogia. Arqueogenealogia. Dispositivo Colonial.

ABSTRACT: This paper aims at establishing theoretical-conceptual relationships between the discourse, the Foucaultian archegenealogy and the coloniality, showing how discourse studies based on/by social struggles can be improved by the notion of "genealogy" as the insurgency of subordinate knowledge, which is a primordial concept in the propositions of Foucault and studies on coloniality. At this point, it is argued the possibility of an intertwining between the two, which is punctuated by dividing the work into two discussion sections: the first deals with the perceptions of discursive analysis by Michel Foucault, distinguishing the archaeological, genealogical and archegenealogical; and the second gives continuity to genealogical discussions, converging also to the idea of Colonial Dispositive as a conceptual construct that also reinforces the discussion about the proposed alliance.

KEYWORDS: Discourse Analysis. Foucault. Genealogy. Archeogenealogy. Colonial Dispositive.

\section{Introdução}

Neste artigo busco estabelecer relações entre o discurso, a arqueogenealogia foucaultiana e a colonialidade para a compreensão da proposição "dispositivo colonial", pertinente às análises que evidenciam as lutas sociais inevitavelmente construídas nas estreitezas entre o discurso e o poder, entendendo o enunciado no tensionamento dos demais acontecimentos sociais e no espraiamento das inserções sócio-históricas. 
Com referências teóricas fraturadas, a partir da decolonialidade (Quijano, 1999; 2005; Mignolo 2003 entre outros) e da genealogia (Foucault, 2010), esta reflexão assenta-se no entrelaçamento necessário entre sujeito $\mathrm{x}$ história $\mathrm{x}$ linguagem à percepção dos estudos discursivos com Foucault para ler a atualidade em relação com o percurso histórico do que nos tornamos.

Posicionada nessa conjuntura de difícil diálogo epistemológico, apresento melhor essas concepções teóricas e a relação desenvolvida entre elas, dividindo o trabalho em duas seções de discussão: a primeira trata das percepções de análise de Michel Foucault, diferenciando as propostas arqueológica, genealógica e arqueogenealógica da análise do discurso foucaultiana; e a segunda se dedica à visibilização do elo que estabelecemos entre os estudos foucaultianos e os estudos decoloniais, convergindo para a ideia de Dispositivo Colonial, como construção que materializa a necessidade teórico-conceitual no campo da análise discursiva que considere o papal fundamental da "colonialidade" na compreensão das conformações sociais na atualidade.

\section{A análise do discurso e o método arqueogenealógico}

Os estudos discursivos têm se desenvolvido como um aparato tanto teórico quanto metodológico, situados na área da Linguagem, mas com diálogos fundamentalmente interdisciplinares. Tal caráter interdisciplinar possibilita diversas áreas do conhecimento se apropriarem dos estudos discursivos como ferramenta metodológica, bem como a área tem se alimentado enquanto construto teórico dos mais variados âmbitos do conhecimento ${ }^{1}$.

De forma geral, nas variadas vertentes, as análises discursivas passam por um processo que parte da superfície linguística do enunciado para se chegar ao objeto discursivo. Nas análises discursivas com Foucault esse processo se concretiza por meio da busca do analista por marcas que evidenciem a que redes de memórias o discurso materializado se filia, preocupando-se com as amarrações sócio-históricas, culturais, políticas e econômicas que atravessam o enunciado. Nas palavras do francês, discurso é

\footnotetext{
1 Sobre os diálogos e divergências entre os autores e seus pensamento acerca do "discurso", ver GREGOLIN, Maria do Rosário. Foucault e Pêcheux na construção da análise do discurso: diálogos e duelos. São Carlos: Claraluz, 2004; e SARGENTINI, Vanice Maria Oliveira. Os estudos do discurso e nossas heranças: Bakhtin, Pêcheux e Foucault. Estudos Linguísticos, XXXV, p. 181-190, 2006. Disponível em: http://www.gel.hospedagemdesites.ws/estudoslinguisticos/edicoesanteriores/4publicaestudos-2006/sistema06/vmos.pdf. Acesso em: 20 jun. 2020.
} 
...um conjunto de enunciados, na medida em que se apoiem na mesma formação discursiva; ele não forma uma unidade retórica ou formal, indefinidamente repetível e cujo aparecimento ou utilização poderíamos assinalar (e explicar, se for o caso) na história: é constituído de um número limitado de enunciados para os quais podemos definir um conjunto de condições de existência. (FOUCAULT, 2014, p. 143)

Entre os vários construtos foucaultianos sobre o discurso, neste trabalho é fundamental compreender o enunciado nos preceitos foucaultianos do discursivo, que o coloca em sua estreita relação com os demais acontecimentos sociais e a história, evidenciando a luta dos saberes que querem se estabelecer como verdade. A partir dessas definições em torno do discurso, passemos então a discutir o que seria o tipo de análise arqueogenealógica. Como ponto de partida, pontuemos que Foucault nos deixou três formas de abordar os enunciados: a arqueologia, a genealogia e a arqueogenealogia, esta última compreendida como a junção das duas anteriores, operacionalizadas a um só tempo.

\subsection{Arqueologia}

Para iniciar essas demarcações, é importante destacar que nesse processo adotado por Foucault com análises históricas para apontar as dispersões de regularidades e descontinuidades sobre os temas os quais se debruçou, precisou, em um determinado momento, explicar seu método, qual era a ferramenta metodológica que fundamentava suas reflexões. Diante dessa interpelação, escreveu em 1969, o livro “A Arqueologia do Saber", onde sistematiza os conceitos que utilizou até aquele momento, as categorias que inaugurou para estudar os saberes, as verdades criadas sobre as coisas.

Vejamos abaixo dois trechos retirados dessa obra, em que o autor explica a arqueologia no âmbito discursivo como propõe:

Esse termo não incita à busca de nenhum começo; não associa a análise a nenhuma exploração ou sondagem geológica. Ele designa o tema geral de uma descrição que interroga o já dito no nível de sua existência: da função enunciativa que nele se exerce, da formação discursiva a que pertence, do sistema geral de arquivo de que faz parte (FOUCAULT, 2014, p. 161).

o que ela [a arqueologia] quer revelar é o nível singular em que a história pode dar lugar a tipos definidos de discurso que têm, eles próprios, seu tipo de historicidade e que estão relacionados com todo um conjunto de historicidades diversas" (FOUCAULT, 2014, p. 201).

O tipo de análise que empreende o uso dessas ferramentas conceituais possibilita ao analista do discurso fazer uma retomada histórica do discurso na perspectiva do 
arquivo, enquanto conjunto de materialidades enunciativas que podem ser interpeladas quanto às condições sócio-históricas de sua emergência.

Para possibilitar então a operacionalização da análise dos enunciados, o francês nos fornece um conjunto de conceitos (tais como enunciado, acontecimento discursivo, objeto discursivo, prática discursiva, formações discursivas, entre outros que ele apresenta ao longo de sua obra) que servem de ferramentas para o labor da análise, o modo de tratar os enunciados no âmbito discursivo, evidenciando que o dito diz para além das coisas ditas, como nos chama atenção o autor.

Neste trabalho, uma definição importante no arcabouço conceitual foucaultiano é a de "descontinuidade" da história. Trata-se de uma ideia fundamental para compreender a análise discursiva com Foucault, sendo uma marca de sua obra a análise de determinados temas (a loucura, a sexualidade, o direito, a clínica, etc.) ao longo do tempo, com o intuito de evidenciar por meio dessa dispersão temporal-linear as emergências de acontecimentos não-lineares e atemporais. Desse modo, o autor mostra que as emergências são regidas pelas condições de possibilidades históricas. Estas seriam as regras que se estabelecem em um determinado momento histórico por força da imbricação de fatores de diversas ordens: social, política, econômica etc.

Dessa forma, nas análises discursivas foucaultiana não devemos esperar apontamentos de sucessões numa lógica de progressão linear ao longo do tempo, mas regularidades e descontinuidades de acontecimentos discursivos não progressivos, possíveis de perceber no espraiamento histórico condicionados aos fatores de tempo e espaço do momento da enunciação.

Nesta história que os homens retraçam com suas próprias ideias e com seus próprios conhecimentos, formular uma teoria geral da descontinuidade, das séries, dos limites, das unidades, das ordens específicas, das autonomias e das dependências diferenciadas. É como se aí onde estivéramos habituados a procurar as origens (...) experimentássemos uma repugnância singular em pensar a diferença, em descrever os afastamentos e as dispersões, em desintegrar a forma tranquilizadora do idêntico. (FOUCAULT, 2014, p. 14-15)

Essas regularidades e descontinuidades consideradas no trabalho foucaultiano reforçam a máxima da análise discursiva de não se interessar pelo nível textual do enunciado, que denota o esforço expressivo do indivíduo ou o uso da língua como atividade racional. Assim, o discurso com Foucault não é o que diz o sujeito, mas é o dito na relação com um conjunto de fatores da exterioridade, onde se pode enxergar no espraiamento sócio-histórico suas regularidades e descontinuidade. Esta, por sua vez, 
não deve ser contornada, mas entendida como uma característica pertencente às condições de aparecimento do discurso e não algo descartável pela sua aparente contradição, pois, segundo Foucault (2014, p. 185), o que surge como contradição evidencia, na verdade, a historicidade do discurso e uma das funções da descontinuidade pode ser, por exemplo, a de

\begin{abstract}
se dispô[r] a descobrir os limites de um processo, o ponto de inflexão de uma curva, a inversão de um movimento regulador, os limites de uma oscilação, o limiar de um funcionamento irregular de uma causalidade circular (...) delimita o campo de que é feito, permite individualizar os domínios, mas só pode ser estabelecida através da comparação desses domínios (FOUCAULT, 2014, p. 10).
\end{abstract}

Nesse exercício, é possível observar a regularidade das descontinuidades ao longo do tempo, delineando a formação de discursos na história geral em relação aos processos econômicos e sociais, fato esse que evidencia a aparente autonomia do discurso em relação à história. O que torna então um trabalho discursivo é o esforço em estabelecer o dito para além da relação significante-significado, da ideia de proposição, frase ou representação, mas como prática discursiva, sistemática; ou seja, enunciados que em determinado momento histórico (e, a partir da emergência, ao longo da história) formam os objetos (discursivos), apoiando-se e retroalimentando uma formação discursiva.

O discurso, portanto, não se limita à língua, a um código linguístico. São manifestações da linguagem expressas nas mais diversas materialidades (não necessariamente na forma da língua) e que estabelecem relações sociais de disputa ou aliança. Assim, os enunciados são considerados numa rede de memória, alocados em discursos ligados por um sistema de relações, inscritos em práticas discursivas. E para definir o regime que rege um enunciado "é preciso reconhecer (...) que não é nem pelo recurso a um sujeito transcendental nem pelo recurso a uma subjetividade psicológica" (FOUCAULT, 2014, p. 66).

Por outro lado, é importante dizer que a arqueologia, como método para análise de enunciados de um arquivo em rede, não garante por si só que o analista empreenda reflexões na abordagem genealógica, a qual compreende uma postura epistemológica de visibilizar os conflitos entre os saberes e as relações de poder.

\title{
1.2 Genealogia
}

Nesse segundo nível de discussão teórico-metodológica, os construtos foucaultianos possibilitam uma percepção mais verticalizada, refinando as proposições 
do autor sobre o discurso em relação com o poder. Para explicar essa face de Foucault, parto da noção "saber-poder", entendo-a como uma compreensão embrionária sobre o poder na sua relação inevitável com o discurso.

Para entender essa relação entre poder e saber, lembremos o que Foucault fala sobre a importância da produção de "saber" sobre algo (ou a produção de um discurso) como estratégico para a operacionalização do poder. Em outros termos, determinados saberes são legitimados e estabelecidos como "verdades" para condicionar os padrões de vida em sociedade, viabilizando o controle social, por isso então o termo "saberpoder".

Nessa conjuntura de produção de saberes com força de "verdade" (ou seja: saberes alinhados à sustentação do poder), a "genealogia" é apontada por Foucault (2010, p. 9) como a "redescoberta exata das lutas e memória bruta dos embates". Segundo ele, a genealogia seria então a luta tanto dos "saberes desqualificados" quanto dos "saberes sepultados da erudição" contra a "tirania dos discursos englobadores". Ou seja, essa tirania trabalha de duas formas: sepultamento de conteúdos históricos em sistematizações formais, por um lado, e, por outro, desqualificação de saberes hierarquicamente inferiores por serem considerados não conceituais, locais, insuficientemente elaborados, o "saber das pessoas". Nisso então se materializa a disputa genealógica, permitindo que “intervenham saberes locais, descontínuos, desqualificados, não legitimados, contra a instância teórica unitária que pretenderia filtrá-los, hierarquizá-los, ordená-los em nome de um conhecimento verdadeiro" (FOUCAULT, 2010, p 10).

Esses efeitos de poder materializados e produzidos nos discursos hegemônicos, englobadores (que, logo, possuem status de verdade) constituem o alvo do embate genealógico, ocupando centralidade nas questões formuladas por Foucault em torno da dominação e do poder, ou seja, o cerne primitivo da guerra, das lutas entre diferentes formas de saber. A noção "saber-poder" expõe justamente o poder de que gozam os saberes legitimados, ao ponto de se tornarem parâmetros sociais, ou seja, únicas verdades aceitáveis. Com isso, Foucault desnaturaliza a verdade por meio da perspectiva discursiva, evidenciando-a em uma rede de poder que confere seu status de verdade e esta, por sua vez, num movimento cíclico, devolve ao poder o fortalecimento de sua estrutura.

Nessa discussão da genealogia o autor chegou a relacionar os saberes sujeitados em oposição ao status de verdade da ciência, como exemplo de um tipo de 
conhecimento legitimado na modernidade em detrimento de outros. Considerando a história de colonização no Brasil, os saberes dos povos indígenas e africanos é um exemplo flagrante de saberes sujeitados, desvalorizados na sociedade nacional pelos efeitos de poder intrínsecos à hierarquização do conhecimento. Por outro lado, o próprio autor explica que não é seu objetivo colocar em questão o saber alcançado de forma científica, mas as relações de poder envolvidas na (des)valorização dos saberes.

Não que elas reivindiquem o direito lírico à ignorância e ao não saber, não que se trate da recusa de saber ou do pôr em jogo, do pôr em destaque os prestígios de uma experiência imediata, ainda não captada pelo saber. Não é disso que se trata. Trata-se da insurreição dos saberes. Não tanto contra os conteúdos, os métodos ou os conceitos de uma ciência, mas de uma insurreição sobretudo e acima de tudo contra os efeitos centralizadores de poder (FOUCAULT, 2010, p. 10).

Sobre a disputa pelo poder localizada nessa discussão acerca da genealogia, destaco ainda a importância de tomá-la como aporte para refletir não apenas no âmbito da produção do conhecimento disciplinar, mas que estendamos esses efeitos de poder da "tirania globalizante" como uma estratégia da hegemonia para estabelecer formas de monopolizar o saber (não necessariamente científico, mas também no que tange o socialmente aceito) sobre os objetos e a circulação desses em discursos. Tal estratégia produz verdades em detrimento do silenciamento de saberes outros e é nessa dinâmica que se beneficiou a colonialidade como padrão de normalidade, logo discurso com status de verdade, legitimando os objetos discursivos que a compõem como confiáveis, válidos, inquestionáveis.

Nesses efeitos de poder em torno da produção de verdade (seja científica ou legitimada pela sociedade na cultura, na religião, na institucionalização de práticas excludentes) como instrumento de controle é que insurge a genealogia, a luta para dessujeitar saberes, fortalecendo-os contra discursos hegemonicamente globalizantes.

Com o avanço temporal, a colonização deixou de existir, porém a colonialidade permanece em nossas subjetividades e estrutura todo o nosso pensamento social, fazendo com que esse silenciamento e apagamento físico e simbólico conferido inicialmente aos povos africanos e indígenas permaneçam afetando na atualidade grupos que não se encaixem no padrão eurocêntrico e neoliberal de existência (socialmente estabelecido como única verdade possível) entre os quais podemos citar os movimentos do campo, das águas, das florestas, indígenas, quilombolas, do povo negro, os LGBTQIA+, entre outros. 
Esses sujeitos produzem subjetividades, saberes que resistem ao padrão global eurocêntrico e hegemônico, aludindo à genealogia foucaultiana como a luta dos saberes sujeitados. Somos desde pequenos formados na normatividade colonial, neoliberal que nos ensina a aversão a toda e qualquer diferença, naturalizando que o campo é espaço exclusivo do agronegócio, que indígenas não existem, que negros e negras são corpos matáveis, que a eliminação simbólica e física de sujeitos subalternizados pela colonialidade "pode" acontecer.

Nisso se evidencia como a hegemonia conta com uma rede de saberes muito fortalecida desde a colonização como verdade que estruturam nossa formação como nação. Por ser estrutural em nossa história o racismo e o patriarcalismo em benefício da promoção político-econômica, compreende-se então a naturalização da desigualdade e da barbárie por meio de estabelecimentos de padrões mundialmente reforçados. Logo, os saberes que propõem um projeto de sociedade que desconstrua esse discurso perverso são frontalmente deslegitimados, combatidos e silenciados. Para isso, a hegemonia possui o controle de diversas ferramentas com papel de retroalimentar a construção das subjetividades dos sujeitos nas normatividades que se filiam a esses padrões, tais como os modelos de família, de estética, de gostos, de saberes e de formas de existir no mundo.

\subsection{Arqueogenealogia}

Apesar de ter demonstrado nas duas subseções anteriores essa diferença entre arqueologia e genealogia, tal atitude não passa de uma estratégia pedagógica a fim de facilitar a compreensão das noções, pois a relação entre elas é imbricada no trabalho arqueogenealógico, a respeito do qual Gregolin (2015, p. 4) faz uma importante explanação sobre como ambas as perspectivas se somam, entendendo que não há uma fratura entre as duas, mas que funcionam mutuamente na descrição e análise de discursos.

Pensando nessa organicidade dos temas e reflexões, podemos, então, compreendê-lo em termos de uma arquegenealogia, sendo o primeiro momento aquele em que, procurando estabelecer a constituição dos saberes em articulação com as práticas sociais, busca responder à questão: como os saberes aparecem e se transformam? A genealogia complementa o exercício arqueológico, sendo então um momento em que Foucault busca o porquê dos saberes, entendendo-os como elementos de um dispositivo cuja natureza é estratégica.

Podemos dizer então que, no nível arqueogenealógico, Foucault coloca seu arcabouço arqueológico a serviço de uma análise que visibiliza as relações do discurso 
com o poder, evidenciando a arqueologia e a genealogia como os dois pilares de sua proposta arqueogenealógica de análise e reflexão. Nas palavras do autor, seu fazer teórico-analítico-metodológico seria então o seguinte: "Enquanto a arqueologia é o método próprio à análise da discursividade local, a genealogia é a tática que, a partir da discursividade local assim descrita, ativa os saberes libertos da sujeição que emergem desta discursividade" (FOUCAULT, 2010, p. 11).

Essas definições dadas até aqui sobre discurso e o método arqueogenealógico, como define Gregolin (2015), permitem então entender essa análise do discurso foucaultiana como metodologia de análise que trata dos discursos na relação com os acontecimentos históricos (sejam sociais, políticos, econômicos...) e com as estruturas de poder normalizadoras da sociedade.

Com isso, a Arqueogenealogia se ergue no arcabouço teórico-metodológico deixado por Foucault como muito pertinente aos estudos discursivos, podendo apontá-la como uma contribuição ao campo da linguagem para analisar e refletir os enunciados como materialidades em estreita relação com a exterioridade social. A Arqueogenealogia nos permite, então, como recomenda Gregolin (2015, p. 9),

Analisar as práticas discursivas para além de sua capacidade de designação e de referenciação significa, na proposta foucaultiana, reconhecer as articulações que os discursos estabelecem com os poderes na produção de verdades historicamente delimitadas. Significa, portanto, que o laço entre discurso e poder é inextricável e que a análise arquegenealógica deve enxergar as articulações que se estabelecem entre eles.

Nisso, os enunciados analisados devem ser relacionados a práticas discursivas fortalecedoras de objetos e formações discursivas ao longo da história. $\mathrm{Na}$ análise das emergências dos discursos, nota-se então um jogo de presença/ausência na dispersão histórica, apontando que as condições de possibilidades históricas para a emergência ou não dos discursos estão diretamente relacionadas à história de lutas dos grupos sujeitados.

Assim, o método arqueogenealógico de Foucault possibilita reflexões na imbricação Sujeito x Linguagem x História na busca por saber "quem somos nós hoje"2, assumindo que somos uma construção sócio-histórica. Ao longo desse percurso histórico, é salutar considerar o caráter não linear, as descontinuidades dos discursos. Sua descontinuidade ao logo da história por determinação das condições de possibilidades históricas.

\footnotetext{
${ }^{2}$ Célebre frase de Foucault para explicar qual a sua busca nos estudos que desenvolve.
} 
A partir disso, noto então uma familiaridade entre a genealogia e a atitude decolonial, que é o levante nos momentos na história em que os "esfarrapados do mundo" de Freire (1972 [2005]) conseguem forçar os regimes de verdade a fazerem uma flexão, regimes esses sustentados por um conjunto de fatores sociais que dão condições ao seu funcionamento, o que Foucault vai chamar de dispositivo ${ }^{3}$.

O balançar desse pêndulo "ascendência/declínio" dos discursos que a análise arqueogenealógica permite é uma ferramenta muito pertinente à compreensão da formação dos discursos, à compreensão do que somos e as possiblidades de sermos ou de termos sido e não fomos. No assentimento das possibilidades para evidenciar as estreitezas entre o arcabouço conceitual foucaultiano e os estudos sobre a colonialidade, no tópico seguinte dedico-me então a traçar esse elo por meio das aproximações entre genealogia e colonialidade às quais justificam tal aliança conforme propomos.

\section{Genealogia, Decolonialidade e Dispositivo Colonial: um elo possível?}

O que foi exposto sobre o poder epistemológico do método arqueogenealógico se dá, especialmente, pela força política que a genealogia confere à arqueologia. Com isso, entendo que a genealogia é uma força central nas proposições de Foucault e é ela que essencialmente nos permite propor a relação entre Foucault e a decolonialidade. A seguir traçarei esse elo e no tópico posterior insiro ainda a discussão sobre dispositivo colonial como a elaboração conceitual de convergência entre ambos.

\subsection{Decolonialidade: os Estudos Decoloniais e possibilidades de aproximação com Foucault}

Os estudos decoloniais partem de problematizações da experiência de conquista nas ex-colônias europeias feitas por pensadores localizados nesse recorte geopolítico, sobretudo a partir dos anos 1990 de forma organizada em grupos renomados como o Grupo Modernidade/Colonialidade, propondo uma tomada de consciência sobre as condições de opressão estruturantes nas sociedades formadas nos territórios colonizados, pautadas por uma hierarquização racial que dá sustentação à colonialidade do poder. Tomemos a explicação de Walsh (2013, p. 25):

posicionamientos, horizontes y proyectos de resistir, transgredir, intervenir, in-surgir, crear e incidir. Lo decolonial denota, entonces, un camino de lucha continuo en el cual se puede identificar, visibilizar y alentar 'lugares' de exterioridad y construcciones alter-(n)ativas.

\footnotetext{
${ }^{3}$ A definição de dispositivo é apresentada no tópico seguinte.
} 
Essa nova proposta de compreensão das relações de poder no mundo é um movimento composto por uma "variedade de contribuições com orientações distintas, mas que apresentam como característica comum o esforço de esboçar, pelo método da desconstrução dos essencialismos, uma referência epistemológica crítica às concepções dominantes de modernidade" (COSTA, 2016, p. 117).

Nessa trama teórica, assinalamos como referências fundamentais o peruano Aníbal Quijano e o argentino Walter de Mignolo, além de outros autores(as) que dialogam com esses dois autores, como Gayatri Spivak e Catherine Walsh, entre muitos outros nomes. Paulo Freire, um dos mais respeitados intelectuais brasileiros também é um nome que precisa ser relacionado essa ruptura teórica e epistemológica, visto que suas obras já tocavam na questão da colonização e desde os anos de 1960 seus livros tiveram muita circulação na América Latina, na África e na Europa. Nessa conjuntura dos que anunciaram as primeiras reflexões decoloniais precisamos apontar ainda Albert Memmi (Os livros Retrato do colonizado e retrato do colonizador, 1947), Aimé Césaire (Discurso sobre o colonialismo, 1950), Fanon (Os condenados da terra, 1961) e Edward Said (Orientalismo, 1978).

No estabelecimento desse pensamento decolonial, consequentemente, os teóricos europeus são posicionados no lugar de produção do conhecimento que a decolonialidade vem questionar e com Foucault, um filósofo francês, não é diferente. Por isso, antevejo as reações de estranhamento e, até, reprovação, para esta tentativa de relacionar o pensamento foucaultiano aos estudos decoloniais. Quanto à isso, destaco, por outro lado, a tentação dos essencialismos na crítica ao essencialismo europeu, considerando a problemática da própria relação de ruptura e diálogo que os autores decoloniais mantêm com o pensamento europeu, conforme destaca Ballestrin (2013) ao avaliar o percurso do Grupo Modernidade/Colonialidade, ao qual se filiam os autores decoloniais aqui citados:

Sua proposta é ao mesmo tempo provocativa e desconfortável, dado o tom de indeferimento radical às conquistas do passado via liberalismo e marxismo e às influências de escolas que o permitiram, afinal, existir. Essa sensação deve-se ao fato de que seus autores dialogam de uma maneira seletiva com os nomes clássicos - modernos e contemporâneos - das ciências sociais e da filosofia, geralmente, apontando suas deficiências na cobrança de um elemento (colonial) sobre o qual o próprio contexto demandava iluminação. Entretanto, uma de suas estratégias consiste mesmo na revisão do que é considerado clássico.

Como filósofo europeu, Foucault é posicionado na contramão do pensamento decolonial, reforçando seu lugar hegemônico na conjuntura da produção do 
conhecimento ocidental. Por outro lado, é possível apontar em sua obra reflexões que tratam da colonização e do papel fundamental do racismo na estruturação de desigualdades nas sociedades. É neste ponto por onde começamos a apontar possibilidades de diálogos, evidenciando que a ideia foucaultiana de genealogia é embrionária no estabelecimento de um elo entre o europeu Foucault e os estudos sobre a (de)colonialidade.

Nas discussões teóricas suscitadas por minha pesquisa de doutorado sobre sociedades indígenas ${ }^{4}$, destacou-se a impossibilidade de não considerar estruturantes dois fatores complementares na história desses povos: a) a luta/resistência racial constituidora da existência indígena ao longo desses mais de 500 anos e b) a colonização como condição para as opressões sobre eles recaídas ao longo da história até os dias atuais. Para fundamentar teoricamente as discussões sobre o primeiro ponto, as noções de genealogia e dispositivo de Foucault acenaram-se como uma saída extremamente produtiva e sobre o segundo a inegável coerência com os estudos decoloniais tornou-se preponderante.

E assim se encaminhou a convergência entre dispositivo e colonialidade para a análise e reflexão das formas de pensar/existir subalternizados pela colonização, silenciadas sistematicamente pelas conjunturas sociais, políticas e econômicas. Nesse percurso histórico no qual o racismo é condição para hierarquizar sujeitos e seus saberes (crítica fundante tanto na perspectiva genealógica quanto nas proposições de colonialidade do poder/saber) é onde acende uma luz para clarificar a possibilidade de caminharmos entre os autores decoloniais e Michel Foucault, sobretudo considerando o posicionamento deste último sobre racismo e colonização.

O racismo vai se desenvolver primo com a colonização, ou seja, com o genocídio colonizador. Quando for preciso matar pessoas, matar populações, matar civilizações, como se poderá fazê-lo, se se funcionar no modo do biopoder? Através dos termos do evolucionismo, mediante o racismo (...). Em linhas gerais, o racismo, acho eu, assegura a função de morte na economia do biopoder [grifo nosso] (FOUCAULT, 2010, p. 216).

Nesse quadro desenhado por Foucault temos a mesma perspectiva discursiva da racialização dos corpos que rege os estudos em torno da colonialidade, e que mais tarde

\footnotetext{
${ }^{4}$ Pesquisa de doutorado "Língua como linha de força do Dispositivo Colonial: os Gavião entre a aldeia e a universidade" (LISBÔA, 2019).
} 
também vai ser apropriada por autores reconhecidos na atualidade como Mbembe (1999) no desenvolvimento da ideia de necropolítica a partir dessas considerações que já fazia Foucault sobre os governos e o poder de gerir a vida e a morte das populações e o racismo intercorrendo essa governamentalidade ${ }^{5}$.

Ao refletir sobre a genealogia e seu poder de refinamento dado ao método arqueogenealógico, como apontamos na seção anterior, a ideia foucaultiana "saberpoder" norteadora da genealogia nos leva inevitavelmente a querer aproximá-la às noções de colonialidade do poder e colonialidade do saber, cunhada por Quijano (1999).

la colonialidad del saber que no sólo estableció el eurocentrismo como perspectiva única de conocimiento, sino que al mismo tiempo, escartó por completo la producción intelectual indígena y afro como 'conocimiento' y, consecuentemente, su capacidad intelectual (QUIJANO, 1999).

Além dessas evidências que mostramos sobre as aproximações por meio da hierarquização dos saberes e da raça tratadas no tópico sobre a genealogia, o próprio Mignolo (2003, p. 16) assume de forma clara e direta sua inspiração no referido filósofo francês.

O que me chamou a atenção, entretanto, foram os entusiásticos partidários e mediadores do pensamento da Europa Ocidental, Derrida, Lacan, Foucault, da Escola de Frankfurt, de Raymond Williams. Isso pareceu-me um exemplo muito sugestivo para compreensão da colonialidade do poder e do conhecimento na América Latina, onde a Europa ainda mantém sua posição epistemológica hegemônica [grifo nosso].

Além desse exemplo, no mesmo livro o autor ainda reforça que para analisar o sistema moderno tomou como referência "em primeiro lugar, Foucault e, em segundo, a Karl Marx e Antônio Gramsci [grifo nosso]". Mais ainda, para elaborar a definição de pensamento liminar, ele também afirma ter dialogado com a noção de insurreição dos saberes subjugados, ou seja, a genealogia proposta por Michel Foucault. "O elo entre a noção de saberes subjugados de Foucault e de saberes subalternos de Darcy Ribeiro permite-me recolocar o dilema do universal/particular através da diferença colonial" (MIGNOLO, 2003, p. 42-44). Nessa última passagem, então, temos a evidência do que defendi sobre a irmandade entre "genealogia" e colonialidade. E não apenas Mignolo

\footnotetext{
5 “A governamentalidade para Foucault (2010) é a atuação governamental para as massas populacionais, o traço de políticas que atingem os corpos em grandes números, interferindo em estatísticas sobre a vida das pessoas. Essa tecnologia do poder, pautada na biopolítica, ou seja, a que rege a vida dos sujeitos (e não individualmente os corpos como no poder disciplinar), tem o racismo como norteador na delimitação das políticas" (LISBÔA, 2019, p. 179).
} 
tem essa inspiração nos estudos foucaultianos, mas a própria vertente de forma generalizada no olhar de Costa (2006, p. 118):

Não obstante, não é difícil reconhecer a relação próxima entre os estudos pós-coloniais e pelo menos três correntes ou escolas contemporâneas. A primeira é o pós-estruturalismo e, sobretudo, os trabalhos de Derrida e Foucault, com quem os estudos pós-coloniais aprenderam a reconhecer o caráter discursivo do social [grifo nosso].

Por fim, trazemos como coroamento dessa convergência, o conceito "dispositivo colonial", proposto por Ivânia Neves (2009, 2015), que, desde minha tese, também venho procurando aprofundar e mostrar possibilidades de sua utilização. Tal formulação alia a compreensão de colonialidade à ideia foucaultiana de dispositivo, constituindo-se como ferramenta que permite abordar discursivamente as relações de poder na sociedade brasileira (e América Latina como território de colonização europeia), inevitavelmente intercortadas pela colonialidade, uma vez que esta envolve em um sistema de opressões todos os grupos sociais marcados pela diferença ao padrão eurocêntrico (homem, branco, hétero e aliado à rede de poder hegemônico) com a normalização do gênero, da raça, da sexualidade e da classe.

\subsection{Dispositivo colonial: $O$ que é o dispositivo e como pensá-lo na colonialidade?}

Refletir sobre objetos de estudos vinculados às opressões de sujeitos subalternizados na América Latina pela colonização a partir dos estudos discursivos muitas vezes exige amarrações epistemológicas desconexas. O dispositivo colonial é fruto dessa necessidade de um aparato teórico-metodológico que permita de forma mais coesa a ligação dos estudos do discurso com a colonialidade e é necessário o percurso reflexivo que proponho neste artigo, a fim de apontar as aproximações possíveis para tal elo, uma vez que, de fato, não é dada tal incursão.

Partindo das teorias discursivas existentes (como não poderia ser diferente, seguindo os critérios de cientificidade), entre os autores dos estudos discursivos, Foucault desponta como o mais próximo dos estudos da decolonialidade, especialmente pela perspectiva genealógica. Mas antes de definir e tratar do dispositivo colonial, falemos resumidamente o que é o dispositivo e seu percurso etimológico.

Gregolin (2015, p. 10) assegura que Foucault nunca discutiu propriamente o conceito de "dispositivo" em nenhum livro, mas deu uma definição numa entrevista concedida em 1977, onde ele exemplifica o dispositivo, dizendo que é um

Conjunto decididamente heterogêneo que engloba discursos, instituições, organizações arquitetônicas, decisões regulamentares, 
leis, medidas administrativas, enunciados científicos, proposições filosóficas, morais, filantrópicas. Em suma, o dito e o não dito são os elementos do dispositivo. O dispositivo é a rede que se pode estabelecer entre estes elementos (FOUCAULT, 2012, p. 364).

O conceito é tratado pelo autor como uma ideia operacional para analisar o poder nas relações sociais, no funcionamento das instituições, leis, etc, nas mais variadas formas de se exercer, administrar o controle social, já que sempre está inscrito num jogo de poder: "É isto, o dispositivo: estratégias de relações de força sustentando tipos de saber e sendo sustentadas por eles". (FOUCAULT, 1999, p. 146).

Numa busca terminológica (dentro da teoria filosófica) em torno do termo dispositivo, Agamben (2005) traça amarrações do conceito foucaultiano com Hegel e um contexto histórico mais amplo, inclusive na perspectiva religiosa. Pela notória aproximação de Foucault com Hegel, o autor defende que este inspirou o primeiro com suas ideias sobre a "positividade" da religião cristã, que "compreende o conjunto das crenças, das regras e dos ritos que em uma determinada sociedade e em um determinado momento histórico são impostos aos indivíduos pelo exterior" (AGAMBEN, 2005, p. $10)$.

A contribuição do autor para a compreensão do conceito de dispositivo inserido numa procedência teológica é que existiria uma relação com o termo oikonomia (economia que em grego tem o sentido de gestão), sendo este uma das facetas divinas à qual se designa a administração, o governo do mundo. Assim, oikonomia ${ }^{6}$ se desenvolveria no âmbito teológico como um cerne para a ideia de "positividade" de Hegel e também, posteriormente, para a ideia de dispositivo, em Foucault.

A positividade de Hegel está para o dispositivo de Foucault no sentido fundamental que rege esses conceitos: o de admitir a existência de um conjunto de processos materializados em instituições e regras que sustentam relações de poder. Nessa aproximação é que Agamben defende tanto a impossibilidade de Foucault desconhecer tal proposição hegeliana como ainda desenvolveu o conceito de dispositivo a partir dela, dizendo que toda a significação dada ao termo positividade (ritos, instituições e regras impostas pela exterioridade aos indivíduos e absorção nos sistemas de práticas dos sujeitos) por Hegel é o que aparece como "dispositivo" nessas falas sumárias de Foucault.

\footnotetext{
6 "um conjunto de praxis, de saberes, de medidas, de instituições cujo objetivo é de administrar, governar, controlar e orientar, em um sentido em que se supõe útil, os comportamentos, os gestos e os pensamentos dos homens" (AGAMBEN, 2005, p. 12).
} 
Por outro lado, Agamben destaca que é possível notar nas formulações de Foucault uma diferença importante do modo hegeliano de pensar a positividade na reconciliação entre dois elementos ou enfatizar o conflito entre eles: "Trata-se para ele [Foucault] antes de investigar os modos concretos em que as positividades (ou os “dispositivos") atuam nas relações, nos mecanismos e nos 'jogos' de poder" (AGAMBEN, 2005, p. 11).

Na busca de evidenciar o conflito de forças no dispositivo, é importante ressaltar a imprescindível influência genealógica sobre os sujeitos "infames", nos termos de Foucault (1977). Tal influência tem o potencial de levar grupos minoritários a lutarem por fissuras nas estruturas de poder e ambicionar novos ordenamentos menos desiguais.

Buscando localizar o termo dispositivo no processo de colonização europeia na América Latina, Ivânia Neves tem se dedicado a defender o conceito dispositivo colonial, propondo que a partir da colonialidade o dispositivo pode ser realocado para compreensão específica de problemáticas sociais como efeitos da colonização. Apesar de reconhecer a grande diferença entre a realidade do louco e do proletariado na Europa pensada por Foucault e a condição do negro e do indígena na América Latina, a autora defende o dispositivo como ferramenta para compreender as heranças coloniais na sociedade brasileira.

Este grande dispositivo, o sistema colonial, engloba o poder colonial das metrópoles europeias e a colonialidade, que representa sua atualização, com seus diferentes matizes, prossegue nas histórias das sociedades amazônicas e em muitas outras histórias da América Latina (NEVES, 2015, p. 31).

Em minha tese, analisei uma singularidade do funcionamento do dispositivo colonial, que repercute no alto índice de evasão dos alunos indígenas das universidades públicas brasileiras. Nesse trabalho também elaborei as condições para operacionalizar o conceito de dispositivo colonial como ferramenta teórico-analítica de discursos, a partir das linhas do dispositivo ("visibilidade" "enunciabilidade", "subjetivação" e "força") propostas por Deleuze (1996), chegando à conclusão de que a língua portuguesa e suas cosmologias, ainda hoje numa relação desigual de poder, representam um grande obstáculo aos povos indígenas e significam a "linha de força" deste dispositivo no Brasil. Remexer as linhas do dispositivo colonial nas universidades fissura esta vontade de verdade colonial comprometida com o discurso da incapacidade e inferioridade do aluno indígena e mostra como o problema está nas estruturas que dificultam ou inviabilizam sua permanência. 
Assim, entendemos o dispositivo colonial como a materialização das relações de poder nos diversos âmbitos da sociedade, responsáveis por estabelecer e manter as verdades necessárias à sustentação da colonialidade do poder. Verdades essas acerca da perspectiva hegemônica eurocêntrica, responsável por enraizar preconceitos, racismos e toda forma de exclusão às manifestações não-europeias nas mais diversas concepções do sensível, no conhecimento, na estética, na cultura e no corpo, o corpo não-europeu como o negro e o indígena. (LISBOA, 2019, p. 77).

As materializações do dispositivo colonial se dão nas engrenagens do funcionamento estrutural da sociedade, tais como: leis, instituições estatais e religiosas, políticas públicas/ações governamentais, produções midiáticas etc, todas se retroalimentando com proposições de normalização de um padrão eurocêntrico e liberal fundamentado no racismo, no heterossexismo, no machismo e na exclusão das camadas mais pobres e de povos/grupos que propõem outros projetos de sociedades não alinhados com o projeto liberal capitalista.

O dispositivo colonial, nessa conjuntura, não pode ser visto como mais um elemento dentro do que nos constitui como sociedade, mas deve ser pensado como o molde da colonialidade, como a estrutura que comporta e reproduz a colonialidade desde as materialidades institucionais do poder até as questões mais subjetivas de definição dos gostos e desejos (LISBÔA, 2019, p. 82-83).

Tais reflexões em torno do dispositivo colonial não são alheias à existência de um sistema mundial de poder (WALLERSTEIN, 2007) que possibilita o estabelecimento de padrões mundialmente espraiados desde a colonização e reforçados pelo advento da globalização, contando ainda com o potencial do capitalismo para o refinamento dessas opressões que afetam os sujeitos não enquadrados no padrão econômico, racial, de gênero e sexualidade (entre outros) historicamente normalizados.

\section{Considerações finais}

Nisso tudo que foi dito, propus refletir sobre a composição do dispositivo colonial, que apesar de se dar por pensamentos distintos, como foi exposto, busquei apontar os fatores que possibilitam aproximações, a fim de responder a necessidade de um instrumental teórico-metodológico para operacionalizar análises discursivas que reconheçam a colonialidade como fundante nas relações de poder na América Latina, como território constituído pela colonização. Esse entendimento requer o reconhecimento da colonialidade como estrutural na organização concreta e subjetiva da 
sociedade e as aproximações com a análise arquegenealógica são feitas buscando evidenciar tal potencialidade no dispositivo colonial.

O apontamento do dispositivo colonial colabora nessas amarrações propostas e, por outro lado, as discussões feitas neste artigo também colaboram no fortalecimento desse conceito, apontando as possibilidades de aproximações entre Foucault e a decolonialidade, especialmente quanto ao destaque dado à genealogia como ligação entre os dois pensamentos, bem como sua força imprescindível para compreensão das resistências.

A proposição do dispositivo colonial com suas linhas constitutivas mostra o quanto é possível avançar no amadurecimento de formas analíticas que instrumentalizem as lutas genealógicas. Visibilizar a busca dos saberes historicamente relegados das legitimações englobadoras, como diz Foucault, é uma forma de o dispositivo colonial reforçar a denúncia contra as injustiças sociais, evidenciando tanto as linhas de força do dispositivo quanto o âmbito da resistência, da produção de subjetividades dos sujeitos.

Com o entendimento de que é papel dos estudos discursivos evidenciar as estreitezas entre o discurso e o poder, acredito ter feito ao longo desse artigo colaborações no sentido metodológico, na compreensão sobre o funcionamento da arqueogenealogia, e também no sentido teórico com as discussões apresentadas sobre: o papel da genealogia tanto na análise discursiva arqueogenealógica, quanto nas fundamentações da decolonialidade; a exposição de fatores que dão coesão às possibilidades de aproximar Foucault à perspectiva da colonialidade no dispositivo colonial; pontuar os avanços do dispositivo até à proposição do dispositivo colonial como uma inovação teórico-metodológica.

\section{REFERÊNCIAS}

AGAMBEN, Giorgio. "O que é um dispositivo?" Conferência. Santa Catarina, Setembro de 2005.

BALLESTRIN, Luciana. América Latina e o giro decolonial. Rev. Bras. Ciênc. Polít. no.11 Brasília May/Aug. 2013. Disponível em: https://www.scielo.br/scielo.php?script=sci_arttext\&pid=S0103$33522013000200004 \#$ back2. Acesso em: 19 jan. 2021.

COSTA, Sérgio. "Desprovincializando a Sociologia: A contribuição pós-colonial." Revista Brasileira de Ciências Sociais. Vol 21. 60, p. 117-134. 2006.

DELEUZE, Gilles. “O que é um dispositivo?" O mistério de Ariana. Lisboa: Vega/Passagens, 1996. 
GREGOLIN, Maria do Rosário. O dispositivo escolar republicano na paisagem das cidades brasileiras: enunciados, visibilidades, subjetividades. Revista Moara - Estudos Linguísticos, Belém, 43ª ed, p. 6-25. jan /jun. 2015.

LISBÔA, Flávia Marinho. "Língua como linha de força do Dispositivo Colonial: os gavião entre a aldeia e a universidade". Tese (Doutorado em Letras, ênfase em Estudos Linguísticos) - Faculdade de Letras, Universidade Federal do Pará, Belém, 2020.

MBEMBE, Achille. Du gouverment privê indirect. Politique africaine mars de 1999, 73 ed.: 103-121.

MIGNOLO, Walter. Colonial and Postcolonial Discourse: Cultural Critique or Academic Colonialism? Latin American Research Revew, 3.28, p. 120-134. 1993.

Histórias Locais / Projetos Globais: Colonialidade, Saberes Subalternos e Pensamento Liminar. Belo Horizonte: UFMG, 2003.

NEVES, Ivânia. Fraturas contemporâneas de histórias indígenas em Belém: sobre mármores e grafites. Revista Maracanan, Rio de Janeiro, n. 24, p. 544-566, maio-ago. 2020.

EtniCidades: os 400 anos de Belém e a presença indígena. Moara, Belém, vol

43. p. 26-44. Jan-jun/2015. Disponível em: https://periodicos.ufpa.br/index.php/moara/article/view/2634/3783. Acesso em: 27 jun. 2020.

FOUCAULT, Michel. História da sexualidade 1: a vontade de saber. São Paulo: Paz e Terra, 2015.

A arqueologia do saber. Rio de janeiro: Forense Universitária, 2014.

Microfísica do Poder. São Paulo: Graal, 2012.

Em defesa da sociedade: curso no Collége de France (1975-1976). São Paulo: WMF Martins Fontes, 2010.

Sobre a História da Sexualidade. In: Microfísica do poder. Org. e trad. Roberto Machado. 17 ed. Rio de Janeiro: Graal, 1999, p. 243-276.

FREIRE, Paulo. Pedagógia do Oprimido. São Paulo: Terra e Paz, 1972.

QUIJANO, Aníbal. Colonialidad del poder, cultura y conocimiento en América Latina" S. Castro-Gómez, O. Guardiola Rivera y C. Millán de Benavides (eds.). Pensar (en) los intersticios. Teoría y práctica de la crítica poscolonial. Vol. Colección Pensar. Bogotá: Centro Editorial Javeriano, 1999.

Colonialidade do poder, Eurocentrismo e América Latina. A colonialidade do saber: eurocentrismo e ciências sociais. Perspectivas. Buenos Aires: CLACSO, Consejo Latinoamericano de Ciencias Sociales, 2005.

WALLERSTEIN, Immanuel. O universalismo europeu: a retórica do poder . São Paulo: Boitempo, 2007.

WALSH, Catherine. Pedagogías decoloniales: Prácticas insurgentes de resistir, (re)existir y (re)vivir. Tomo I. Quito: Ab ya-Ya la, 2013. 